Marion Nestle, PhD MPH

Michael F. Jacobson, PhD

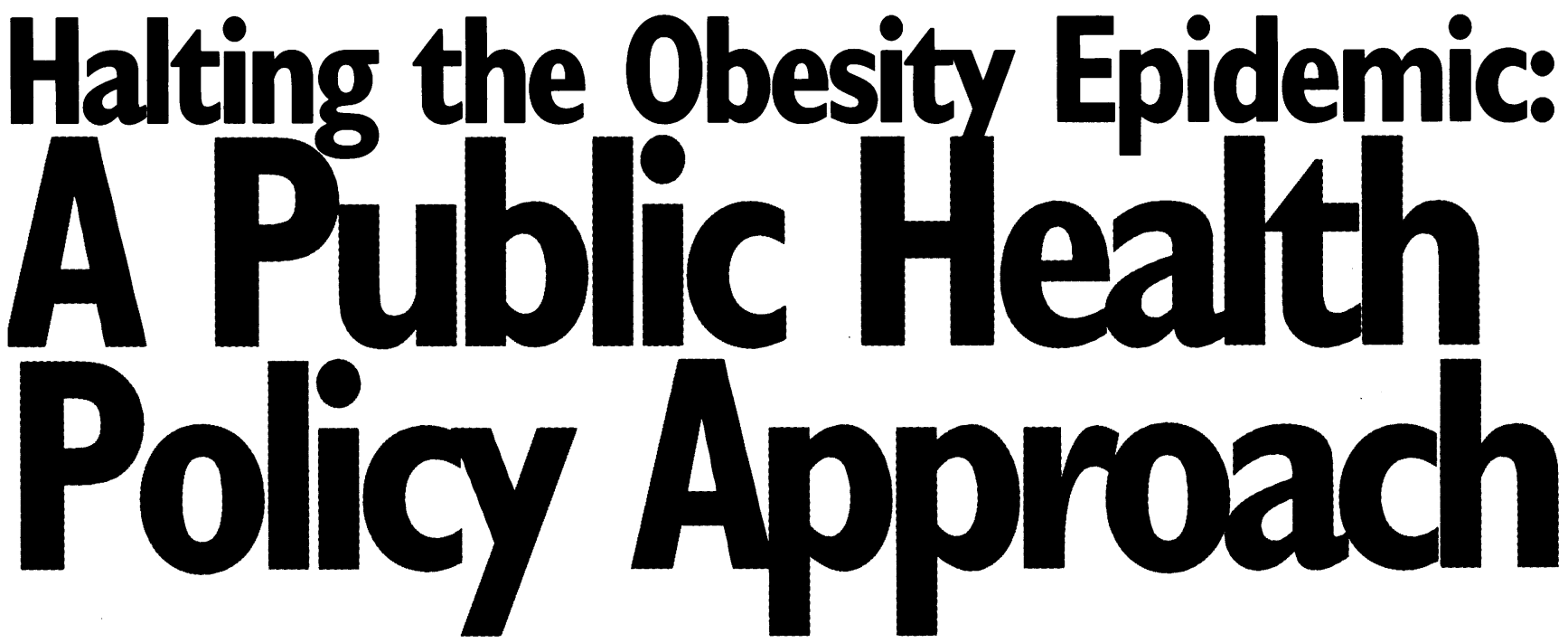

$S Y N O P S$ I

Traditional ways of preventing and treating overweight and obesity have almost invariably focused on changing the behavior of individuals, an

approach that has proven woefully

inadequate, as indicated by the rising

rates of both conditions. Considering the many aspects of American culture that promote obesity, from the proliferation of fast-food outlets to almost universal reliance on

automobiles, reversing current trends will require a multifaceted public health policy approach as well as considerable funding. National leadership is needed to ensure the participation of health officials and researchers, educators and legislators, transportation experts and urban planners, and businesses and nonprofit groups in formulating a public health campaign with a better chance of success. The authors outline a broad range of policy recommendations and suggest that an obesity prevention campaign might be funded, in part, with revenues from small taxes on selected products that provide "empty" calories-such as soft drinks-or that reduce physical activity - such as automobiles.
IN 1974, AN EDITORIAL IN The Lancet identified obesity as "the most important nutritional disease in the affluent countries of the world,"' yet a quarter century later, its prevalence has increased sharply among American adults, adolescents, and children. ${ }^{2-4}$ The deleterious effects of obesity on chronic disease risk, morbidity, and mortality,6; its high medical, psychological, and social costs ${ }^{7,8}$; its multiplicity of causes; its persistence from childhood into adulthood ${ }^{10}$; the paucity of successful treatment options ${ }^{11}$; the hazards of pharmacologic treatments ${ }^{12}$; and the complexities of treatment guidelines 13 all argue for increased attention to the prevention of excessive weight gain starting as early in life as possible. Prevention, however, requires changes in individual behavioral patterns as well as eliminating environmental barriers to healthy food choices and active lifestyles — both exceedingly difficult to achieve.

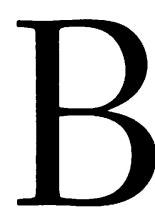

ecause obesity results from chronic consumption of energy (calories) in excess of that used by the body, prevention requires people to balance the energy they consume from food and drinks with the energy expended through metabolic and muscular activity. Although the precise relationship between the diet and activity components of this "equation" is still under investigation, ${ }^{14,15}$ it is intuitively obvious that successful prevention strategies-individual and societal-must address both elements. ${ }^{16}$ 


\section{OBESITY $=$}

Solom THE TRUTHRBOUT MUEIGNT COUTROL \&H

THESAVE-YOUR-LIFE DIET DAVID REUBEN,M.D.

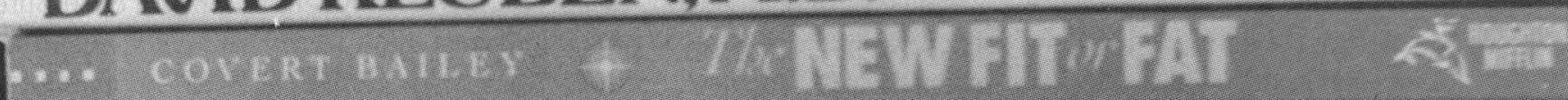

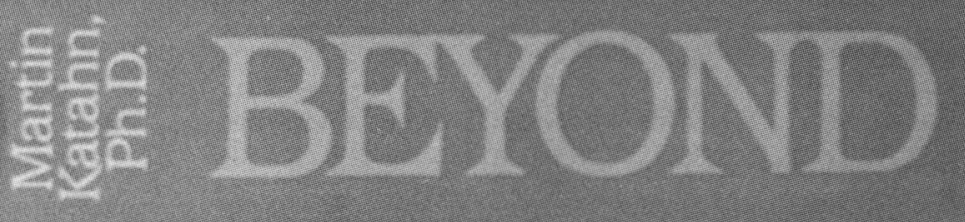

LOSE IVECIII $\frac{\text { GUIDEBOOK }}{1994}$ 站言

\section{THINMER 月Т I月९ STEVEN LAMm, M.D. \\ Therer}

Barbara Edelstein,M.D. The Underburner's Diet

Katahn THE TRI-COLOR DIET

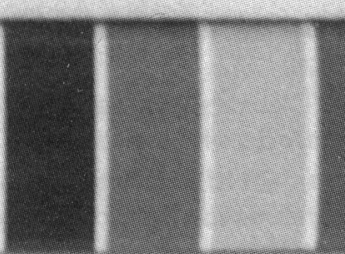

$q^{=}$

SOUTHAMPTON STUART BERGER.M.D. DIET

WIIII MIROLA COUIEY

SIMON AND

SCIILSTK

50 WAVS TO LOSE YOUR BLUBBER

Dr. Paul G. Varnas

ta

\section{The DIET CENTER PROGRAM FERGISON}

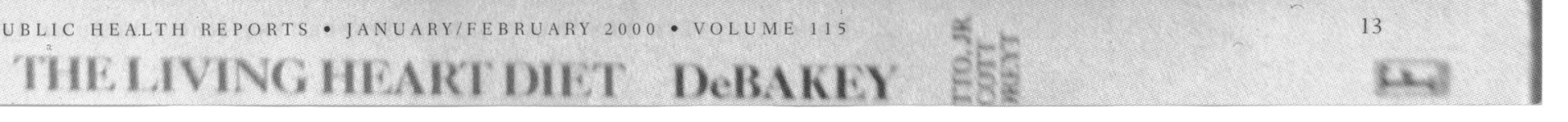




\section{GUIDELINES FOCUS ON INDIVIDUALS}

Concern about obesity is not new. By 1952, the American Heart Association had already identified obesity as a cardiac risk factor modifiable through diet and exercise. ${ }^{17}$ Subsequently, a number of federal agencies and private organizations devoted to general health promotion or to prevention of chronic conditions for which obesity is a risk factor-coronary heart disease, cancer, stroke, and diabetes-issued guidelines advising Americans to reduce energy intake, raise energy expenditure, or do both to maintain healthy weight (Figure 1). Typically, these guidelines focused on individuals and tended to state the obvious. For example, the otherwise landmark 1977 Senate report on diet and chronic disease prevention, Dietary Goals for the United States, omitted any mention of obesity. (The second edition was amended to advise: "To avoid overweight, consume only as much energy [calories] as is expended; if overweight, decrease energy intake and increase energy expenditure."18) Overall, the nearly halfcentury history of such banal recommendations is notable for addressing both physical activity and dietary patterns, but also for lack of creativity, a focus on individual behavior change, and ineffectiveness.

Only rarely did such guidelines deal with factors in society and the environment that might contribute to obesity. Participants in the 1969 White House Conference on Food, Nutrition, and Health recommended a major

Figure I. Examples of policy guidelines published by US government agencies and health organizations for prevention of obesity through diet, exercise, or both

1952 American Heart Association: Food for Your Heart ${ }^{17}$

1965 American Heart Association: Diet and Heart Disease

1968 American Heart Association: Diet and Heart Disease

1970 White House Conference on Food, Nutrition, and Health $^{19}$

1971 American Diabetes Association: Principles of Nutrition and Dietary Recommendations

1974 National Institutes of Health: Obesity in Perspective

1974 American Heart Association: Diet and Coronary Heart Disease

1977 National Institutes of Health: Obesity in America ${ }^{20,22}$

1977 US Senate Select Committee on Nutrition and Human Needs: Dietary Goals for the United States, 2nd Edition $^{18}$

1978 American Heart Association: Diet and Coronary Heart Disease

1979 US Department of Health, Education, and Welfare: Healthy People: The Surgeon General's Report on Health Promotion and Disease Prevention

1979 National Cancer Institute: Statement on Diet, Nutrition, and Cancer

1979 American Diabetes Association: Principles of Nutrition and Dietary Recommendations

1980 US Department of Agriculture and US Department of Health and Human Services: Dietary Guidelines for Americans $^{24}$

1984 National Institutes of Health: Lowering Blood Cholesterol to Prevent Heart Disease

1984 American Cancer Society: Nutrition and Cancer: Cause and Prevention

1985 National Institutes of Health: Consensus Development Conference Statement

1985 US Department of Agriculture and US Department of Health and Human Services: Dietary Guidelines for Americans, 2nd Edition

1986 American Heart Association: Dietary Guidelines for Healthy American Adults
1986 American Diabetes Association: Nutritional Recommendations and Principles

1988 US Department of Health and Human Services: The Surgeon General's Report on Nutrition and Health

1988 American Heart Association: Dietary Guidelines for Healthy American Adults

1988 National Cancer Institute: NCI Dietary Guidelines

1988 National Heart, Lung, and Blood Institute: National Cholesterol Education Program

1989 National Research Council: Diet and Health: Implications for Reducing Chronic Disease Risk

1990 US Department of Agriculture and US Department of Health and Human Services: Dietary Guidelines for Americans, 3rd Edition

1991 American Cancer Society: Guidelines on Diet, Nutrition, and Cancer

1993 National Heart, Lung, and Blood Institute: National Cholesterol Education Program

1994 American Diabetes Association: Nutrition Principles for the Management of Diabetes and Related Complications

1995 US Department of Agriculture and US Department of Health and Human Services: Dietary Guidelines for Americans, 4th Edition

1996 American Heart Association: Dietary Guidelines for Healthy American Adults

1996 American Cancer Society: Guidelines on Diet, Nutrition, and Cancer Prevention

1996 American Diabetes Association: Nutrition Recommendations and Principles

1997 American Heart Association: Guide to Primary Prevention of Cardiovascular Diseases

1997 World Cancer Research Fund and American Institute for Cancer Research: Food, Nutrition and the Prevention of Cancer: A Global Perspective

1999 American Heart Association: Preventive Nutrition: Pediatrics to Geriatrics

NOTE: References not indicated are available from the authors on request. 
national effort to reverse the trend toward inactivity in the population through a massmedia campaign focused on milder forms of exercise such as walking or stair-climbing; school physical education programs; and federal funding for community recreation facilities. ${ }^{19}$ The 1977 Dietary Goals report described certain societal influences on dietary intake, such as television advertising, but made no recommendations for government action beyond education, research, and food labeling. ${ }^{18}$

The most notable exception was the report of a 1977 conference organized by the

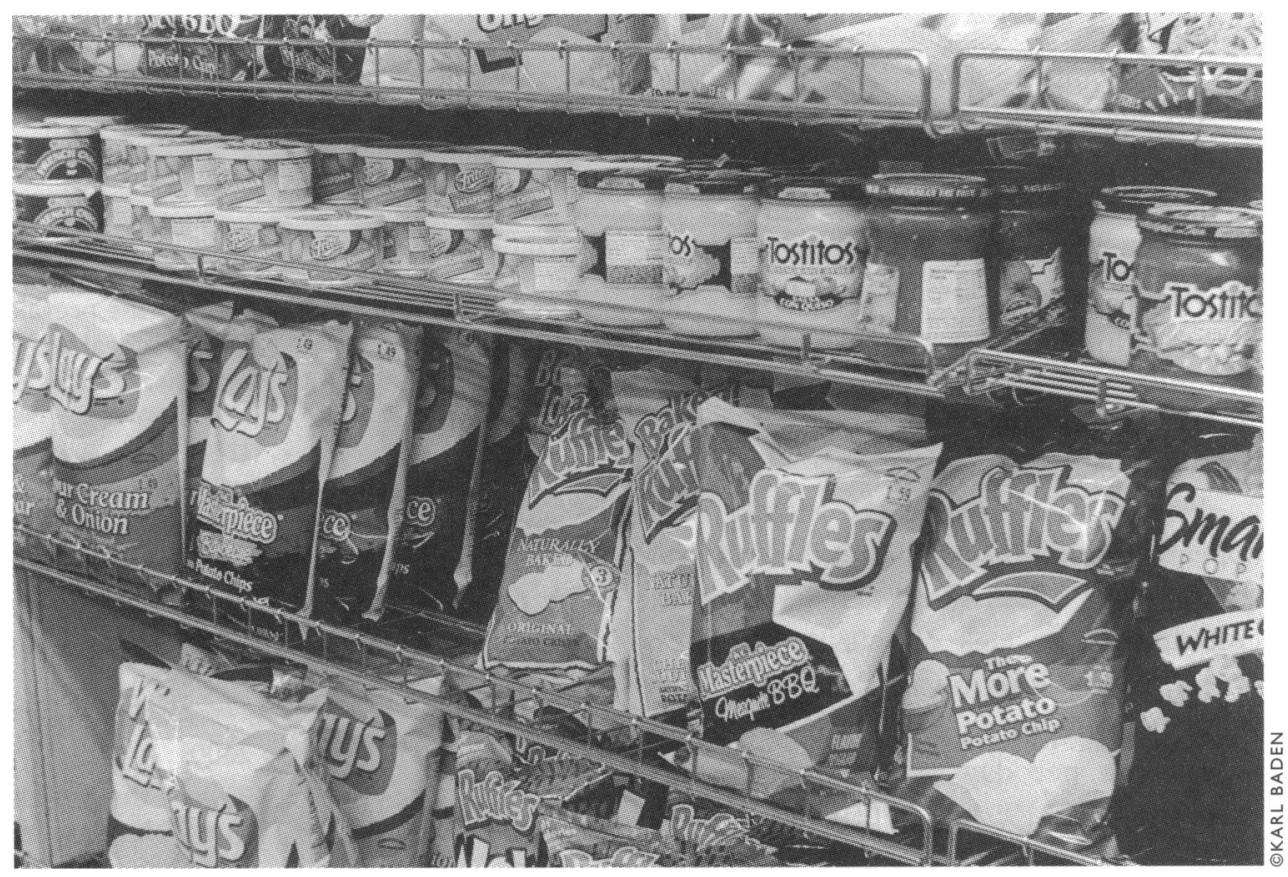

National Institutes of Health (NIH) to review research and develop recommendations for obesity prevention and management. In one paper, A.J. Stunkard thoroughly reviewed social and environmental influences on obesity. ${ }^{20}$ As a result, the conference report included an extraordinarily broad list of proposals for federal, community, and private actions to foster dietary improvements and more active lifestyles. These ranged from coordinated health education and model school programs to changes in regulations for grades of meat, advertising, taxes, and insurance premiums. ${ }^{21}$ Some of the proposals cut right to the core of the matter: "Propose that any national health insurance program...recognize obesity as a disease and include within its benefits coverage for the treatment of it." "Make nutrition counseling reimbursable under Medicare." and "Fund demonstration projects at the worksite."22 Perhaps because the recommendations took 23 pages to list, conveyed no sense of priority, would be expensive to implement, but specified no means of funding, they were largely ignored and soon forgotten. Subsequent reports on obesity prevention continued to emphasize individual approaches to decreasing energy intake and increasing energy expenditure without much consideration of the factors in society that act as barriers to such approaches.

\section{NATIONAL OBJECTIVES}

Prevention of obesity by individuals and population groups has been an explicit goal of national public health policy since 1980 (see Figure 2). In developing its successive 10year plans to reduce behavioral risks for disease through specific and measurable health objectives, the US Public Health Service (PHS) said that the government should "lead, catalyze, and provide strategic support" for implementation through collaboration with professional and industry groups. ${ }^{23}$ In developing the specific Promoting Health/Preventing Disease objectives for obesity prevention and the methods to implement them, PHS suggested that government agencies do such things as work with public and private agencies to distribute copies of the Dietary Guidelines for Americans ${ }^{24}$ and other educational materials; encourage development of nutrition education and fitness programs through grants to states; and support research on methods to prevent and control obesity among adults and children. Although these obesity objectives were assigned to the Department of Health and Human Services (DHHS), the implementation activities were distributed among multiple agencies within the Department, with no one agency taking lead responsibility. Thus, the Centers for Disease Control and Prevention (CDC) were to encourage adoption of model school curricula, the Food and Drug Administration (FDA) was to develop a mass-media campaign to educate the public about food labels, and NIH was to sponsor workshops and research on obesity. Implementation steps to achieve the physical activity objectives were distributed among at least nine federal agencies. ${ }^{25}$ The words used to describe the implementation steps reflected-and continue to reflect-political and funding realities. Government agencies can encourage, publicize, and cooperate with-but usually cannot implement-programs to achieve national obesity objectives.

Nevertheless, evidence of rising rates of obesity in the late $1980 \mathrm{~s}$ and $1990 \mathrm{~s}^{2,13}$ has focused increasing attention on the need for prevention strategies. In PHS's second 10-year plan, Healthy People 2000, the section on physical activity and fitness appears first among the 22 
priority areas for behavior change, and the nutrition objectives appear second, emphasizing PHS's view of obesity as a priority public health problem. Among the objectives in these areas, reducing rates of overweight among adults and adolescents appeared second in order only to prevention of cardiovascular disease. Healthy People 2000 listed specific objectives for promotion of nutrition and physical education in schools, work sites, and communities-public health approaches that would surely create a more favorable environment for prevention of obesity (see Figure 2). ${ }^{26}$

Despite these efforts, the activity levels of Americans appear to have changed little, if at all, from the 1970s to the $1990 \mathrm{~s},{ }^{5,27}$ Discerning such trends is exceedingly difficult due to the lack of reliable methods for measuring energy expenditure in the population. Moreover, the average caloric intake reported by Americans rose from 1826 kilocalories per day $(\mathrm{kcal} / \mathrm{d})$ in 1977-1978 and 1774 $\mathrm{kcal} / \mathrm{d}$ in $1989-1991^{28}$ to $2002 \mathrm{kcal} / \mathrm{d}$ in $1994-1996 .{ }^{29}$ No matter how imprecise the data, these trends suggest why average body weights are increasing so significantly. According to data from the 1976-80 and 1988-1994 National Health and Nutrition Examination Surveys, the prevalence of overweight (defined as at or above the 85th percentile of body mass index [BMI] in 1976-1980) rose from $25.4 \%$ to $34.9 \%$ among American adults, from $24.1 \%$ to $33.3 \%$ among men and from $26.5 \%$ to $36.4 \%$ among women; nearly doubled among children ages $6-11$ years from $7.6 \%$ to $13.7 \%$; and rose from $5.7 \%$ to $11.5 \%$ among adolescents. ${ }^{2,4}$ (The BMI is defined as body weight in kilograms divided by height in meters squared $\left[\mathrm{kg} / \mathrm{m}^{2}\right]$.) According to the results of telephone surveys conducted by the CDC, the prevalence of obesity (defined as a BMI $\geq 30$ ), increased from $12 \%$ to nearly $18 \%$ in just the few years from 1991 to $1998 .^{2}$ Trends in prevention and treatment of obesity are also moving in precisely the wrong direction. The proportions of schools offering physical education, overweight people who report dieting and exercising to lose weight, and primary-care physicians who counsel patients about behavioral risk factors for obesity and other conditions have all declined. ${ }^{?}$

In response to these alarming developments, the third PHS 10-year plan, Healthy People 2010, continues to emphasize goals related to regular exercise, noting that people with risk factors for coronary heart disease, such as obesity and hypertension, may particularly benefit from physical activity. ${ }^{30}$ The first three objectives in the nutrition section now focus on increasing the prevalence of healthy weight (BMI 19-25), reducing the prevalence of obesity, and reducing overweight among children and adolescents (Figure 2). But the plan offers little guidance as to how the objectives are expected to be achieved beyond calling for "a concerted public effort" in that direction..$^{30}$
Figure 2. Principal US Public Health Service objectives for reducing the prevalence of obesity through improved nutrition and physical fitness

\author{
Promoting Health/Preventing Disease $(1980)^{23}$ \\ By 1990:
}

- Reduce the prevalence of significant overweight (>120\% ideal weight) among adult men to $10 \%$ and among adult women to $17 \%$ without nutritional impairment.

- $50 \%$ of the overweight population should have adopted weight loss regimens, combining an appropriate balance of diet and physical activity.

- $90 \%$ of adults should understand that to lose weight people must either consume foods that contain fewer calories or increase physical activity, or both.

Healthy People $2000(1990)^{26}$

By 2000:

- Reduce the prevalence of overweight to no more than $20 \%$ of adults and $15 \%$ of adolescents.

- Increase to $50 \%$ the proportion of overweight people ages 12 and older who have adopted sound dietary practices combined with regular physical activity to attain an appropriate body weight.

Healthy People $2010(2000)^{30}$

By 2010:

- Increase to at least $60 \%$ the prevalence of healthy weight (body mass index [BMI] 19-25) among adults.

- Reduce to $15 \%$ the proportion of adults with BMI $\geq 30$.

- Reduce to $5 \%$ or less the prevalence of obesity in children and adolescents.

- Increase the proportion of schools that teach essential nutrition topics such as balancing food intake and physical activity in at least three grades.

- Increase to at least $85 \%$ the proportion of worksites that offer nutrition education and/or weight management programs for employees.

- Increase to at least $75 \%$ the proportion of primary care providers who provide or order weight reduction services for patients with cardiovascular disease and diabetes mellitus diagnoses.

The Healthy People 2010 objectives also address obesity indirectly through specific objectives for increasing moderate and physical activity among children and adults; for encouraging consumption of more healthful diets; for increasing the use of nutrition labels; for reducing sources of unnecessary calories in food products and in restaurant and school meals; for increasing nutrition and physical education in schools; and for improving access to community recreational facilities. ${ }^{30}$

\section{BARRIERS TO OBESITY PREVENTION}

Although the impact of obesity on health has been recognized for nearly a half century and its increasing prevalence among adults and children shows no sign of reversal, 
exchange for mandatory viewing of commercials by students, ${ }^{38}$ and school district contracts for exclusive marketing of one or another soft drink in vending machines and sports facilities. ${ }^{39}$ Advertising directly affects the food choices of children, ${ }^{40}$ who now have far more disposable income than they had several decades ago and far greater influence on their parents' buying habits. ${ }^{41}$

Americans spend about half of their food budget and consume about one-third their daily energy ${ }^{42}$ on meals and drinks consumed outside the home, where it is exceedingly difficult to estimate the energy content of the food. About 170,000 fast-food restaurants ${ }^{43}$ and three million soft drink vending machines ${ }^{44}$ help ensure that Americans are not more than a few steps from immediate sources of relatively non-nutritious foods. As a Coca-Cola Company executive proclaimed, "[T] o build pervasiveness of our products, we're putting ice-cold Coca-Cola classic and our other brands within reach, wherever you look: at the supermarket, the video store, the soccer field, the gas station-everywhere." 45

Food eaten outside the home, on average, is higher in fat and lower in micronutrients than food prepared at home. ${ }^{42}$ Many popular table-service restaurant meals-lunch or dinner-provide 1000 to $2000 \mathrm{kcal}$ each ${ }^{46}$ amounts equivalent to $35 \%$ to $100 \%$ of a full day's energy requirement for most adults. ${ }^{47}$ Restaurants and movie theaters charge just a few cents more for larger-size orders of soft drinks, popcorn, and French fries, and the standard serving sizes of these and other foods have increased greatly in the past decade ${ }^{48}$ For example, in the 1950s, Coca-Cola was packaged only in 6.5-oz bottles; single-serving containers expanded first to 12-oz cans and, more recently, to 20 -oz bottles. A 12 -oz soft drink provides about $150 \mathrm{kcal}$, all from sugars, but contains no other nutrients of significance. ${ }^{49}$

Taken together, such changes in the food environment help explain why it requires more and more will power for Americans to maintain an appropriate intake of energy.

Energy expenditure. Influencing Americans to increase energy expenditure is as daunting a task as encouraging reductions in energy intake. Twentieth-century labor-saving devices, from automobiles to e-mail, are ubiquitous and have reduced energy needs, as has the shift of a large proportion of the workforce from manual labor to white-collar jobs that require nothing more active than pressing keys on a computer. ${ }^{50}$ Wonders of modern civilization such as central heating lessen the energy cost of maintaining body temperature, and air conditioning makes it much more comfortable on hot summer days to stay inside and watch television or play computer games than to engage in outdoor activities. Dangerous neighborhoods - or the perception of dangerdiscourage people from walking dogs, pushing strollers, playing ball, jogging, or permitting children to play outdoors. ${ }^{51}$ Many suburban neighborhoods are structured for the convenience of automobile drivers; they may not have sidewalks and may lack stores, entertainment, or other destinations within walking distance. Meanwhile, the decline in tax support for many public school systems and the need to fulfill competing academic priorities have forced them to relegate physical education to the category of "frill." Many school districts have had to eliminate physical education classes entirely, and fewer and fewer schools offer any opportunity for students to be physically active during the school day. ${ }^{6}$ Such barriers make it clear why an attempt to "detoxify" the present environment and create one that fosters healthful activity patterns deserves far more attention than it has received since the 1977 recommendations in Obesity in America. ${ }^{20,22}$

\section{Public health Approaches}

In an environment so antagonistic to healthful lifestyles, no quick and easy solution to the problem of obesity should be expected. Meaningful efforts must include the development of government policies and programs that address both the "energy in" and "energy out" components of weight maintenance. Although privately funded campaigns to educate the public and mobilize physicians to combat obesity, such as Shape Up America, ${ }^{52}$ are useful adjuncts, they cannot be expected to achieve significant populationwide behavior change. What is needed is substantial involvement of and investment by government at all levels. Governmental policies and programs affect many of the environmental determinants of poor diets and sedentary lifestyles. Communities, workplaces, schools, medical centers, and many other venues are subject to federal and other governmental regulations that could be modified to make the environment more conducive to healthful diet and activity patterns. Just as the environmental crisis spurred the public to make a huge financial investment in seeking solutions, so should the obesity epidemic.

In Figure 3, we provide recommendations for a variety of such modifications along with suggestions for new policies targeted to obesity prevention. These recommendations, reflecting the disparate influences on diet and activity, address education, food regulation and advertising, food assistance, health care and the training of health professionals, transportation and urban development, taxation, and the development of federal policy. We offer the suggestions, some of which have been proposed by others, ${ }^{20,22,53,54}$ to stimulate discussion of a much wider range of approaches than is typically considered. In doing so, we suggest changes in existing policies and practices ${ }^{55}$ that affect health behaviors. We believe these proposals are politically and economically feasible and, collectively, capable of producing a significant effect in helping people to maintain healthy weight. Each of the suggestions could benefit from further discussion and analysis. Here, we comment on just a few of them. 
Using media campaigns. Media advertising should be a vital part of any campaign to reduce obesity through promotion of positive changes in behavior, such as eating more fruits, vegetables, and whole grains; switching to lower-fat meat or dairy products; eating fewer hamburgers and steaks; and drinking water instead of soda. Campaigns of this kind can be remarkably effective. For example, the Center for Science in the Public Interest's "1\% Or Less" program doubled the market share of low-fat and fat-free milk in several communities through intensive, seven-

\section{Figure 3. Reducing the prevalence of obesity: policy recommendations}

\section{Education}

- Provide federal funding to state public health departments for mass media health promotion campaigns that emphasize healthful eating and physical activity patterns.

- Require instruction in nutrition and weight management as part of the school curriculum for future health-education teachers.

- Make a plant-based diet the focus of dietary guidance.

- Ban required watching of commercials for foods high in calories, fat, or sugar on school television programs (for example, Channel One).

- Declare and organize an annual National "No-TV" Week.

- Require and fund daily physical education and sports programs in primary and secondary schools, extending the school day if necessary.

- Develop culturally relevant obesity prevention campaigns for high-risk and low-income Americans.

- Promote healthy eating in government cafeterias, Veterans Administration medical centers, military installations, prisons, and other venues.

- Institute campaigns to promote healthy eating and activity patterns among federal and state employees in all departments.

\section{Food labeling and advertising}

- Require chain restaurants to provide information about calorie content on menus or menu boards and nutrition labeling on wrappers.

- Require that containers for soft drinks and snacks sold in movie theaters, convenience stores, and other venues bear information about calorie, fat, or sugar content.

- Require nutrition labeling on fresh meat and poultry products.

- Restrict advertising of high-calorie, low-nutrient foods on television shows commonly watched by children or require broadcasters to provide equal time for messages promoting healthy eating and physical activity.

- Require print advertisements to disclose the caloric content of the foods being marketed.

\section{Food assistance programs}

- Protect school food programs by eliminating the sale of soft drinks, candy bars, and foods high in calories, fat, or sugar in school buildings.

- Require that any foods that compete with school meals be consistent with federal recommendations for fat, saturated fat, cholesterol, sugar, and sodium content.

- Develop an incentive system to encourage Food Stamp recipients to purchase fruits, vegetables, whole grains, and other healthful foods, such as by earmarking increas- es in Food Stamp benefits for the purchase of those foods.

\section{Health care and training}

- Require medical, nursing, and other health professions curricula to teach the principles and benefits of healthful diet and exercise patterns.

- Require health care providers to learn about behavioral risks for obesity and how to counsel patients about health-promoting behavior change.

- Develop and fund a research agenda focused on behavioral as well as metabolic determinants of weight gain and maintenance, and on the most cost-effective methods for promoting healthful diet and activity patterns.

- Revise Medicaid and Medicare regulations to provide incentives to health care providers for nutrition and obesity counseling and other interventions that meet specified standards of cost and effectiveness.

\section{Transportation and urban development}

- Provide funding and other incentives for bicycle paths, recreation centers, swimming pools, parks, and sidewalks.

- Develop and provide guides for cities, zoning authorities, and urban planners on ways to modify zoning requirements, designate downtown areas as pedestrian malls and automobile-free zones, and modify residential neighborhoods, workplaces, and shopping centers to promote physical activity.

\section{Taxes}

- Levy city, state, or federal taxes on soft drinks and other foods high in calories, fat, or sugar to fund campaigns to promote good nutrition and physical activity.

- Subsidize the costs of low-calorie nutritious foods, perhaps by raising the costs of selected high-calorie, lownutrient foods.

- Remove sales taxes on, or provide other incentives for, purchase of exercise equipment.

- Provide tax incentives to encourage employers to provide weight management programs.

\section{Policy development}

- Use the National Nutrition Summit to develop a national campaign to prevent obesity.

- Produce a Surgeon General's Report on Obesity Prevention.

- Expand the scope of the President's Council on Physical Fitness and Sports to include nutrition and to emphasize obesity prevention.

- Develop a coordinated federal implementation plan for the Healthy People 2010 nutrition and physical activity objectives. 
week paid advertising and public relations campaigns that cost as little as 22 cents per person. ${ }^{56-58}$ Those efforts illustrate that advertising can be an affordable, effective method for promoting dietary change- even in the context of media advertising for less nutritious foods. Similar mass-media motivational campaigns could be developed to encourage people to walk, jog, bicycle, and engage in other enjoyable activities that expend energy.

\section{Discouraging TV watching and junk-food advertis-} ing. Anti-obesity measures need to address television watching, a major sedentary activity as well as one that exposes viewers to countless commercials for high-calorie foods. The average American child between the ages of 8 and 18 spends more than three hours daily watching television and another three or four hours with other media. ${ }^{59}$ Television is an increasingly well-established risk factor for obesity and its health consequences in both adults and children. ${ }^{60,61}$ At least one study now shows that reducing the number of hours spent watching television or playing video games is a promising approach to preventing obesity in children. ${ }^{62}$ Government and private organizations could sponsor an annual "No TV Week" to remind people that life is possible, even better, with little or no television and that watching television could well be replaced by physical and social activities that expend more energy. The Department of Education and DHHS could sponsor a national campaign, building on previous work by the nonprofit TVFree America. ${ }^{63}$

Advertisements for candy, snacks, fast foods, and soft drinks should not be allowed on television shows commonly watched by children younger than age 10 . Researchers have shown that younger children do not understand the concept of advertising - that it differs from program content and is designed to sell, not inform-and that children of all ages are highly influenced by television commercials to buy or demand the products that they see advertised ${ }^{64}$ It makes no sense for a society to allow private interests to misshape the eating habits of the next generation, and it is time for Congress to repeal the law that blocks the Federal Trade Commission from promulgating industry-wide rules to control advertising during children's television programs. ${ }^{65}$

Promoting physical activity. Federal and state government agencies could do more to make physical activity more attractive and convenient. They could provide incentives to communities to develop safe bicycle paths and jogging trails; to build more public swimming pools, tennis courts, and ball fields; to pass zoning rules favoring sidewalks in residential and commercial areas, traffic-free areas, and traffic patterns that encourage people to walk to school, work, and shopping; and safety protection for streets, parks, and playgrounds. Government could also provide incentives to use mass transit, and disincentives to drive private cars, thereby encouraging people to walk to bus stops and train stations.

Reaching children through the schools. State boards of education and local school boards have an obligation to promote healthful lifestyles. Physical education should again be required, preferably on a daily basis, to encourage students to expend energy and to help them develop lifelong enjoyment of jogging, ball games, swimming, and other low-cost activities. School boards should be encouraged to resist efforts of marketers to sell soda and highcalorie, low-nutrient snack foods in hallways and cafeterias. Congress could support more healthful school meals by insisting that the US Department of Agriculture (USDA) set stricter limits on sales of foods high in energy (calories), fat, and sugar that compete with the sale of balanced breakfasts and lunches.

Adjusting food prices. Price is a factor in food purchases. Lowering by half the prices of fruits and vegetables in vending machines and school cafeterias can result in doubling their sales. ${ }^{66}$ The government could adopt policies to decrease the prices of more healthful foods and increase the prices of foods high in energy ${ }^{67}$ Local governments and the media might offer free publicity, awards, or other incentives to restaurants to offer free salads with meals, to charge more for less nutritious foods, and to reduce the prices of more nutritious foods.

\section{Financing OBESITy Prevention}

The principal barrier to meaningful health-promotion programs is almost always lack of funds, and the educational campaigns and certain other measures we propose would not be inexpensive. But to put such costs in perspective, it is important to understand that the annual costs of direct health care and lost productivity resulting from obesity and its consequences have been estimated at $5.7 \%$ of total US health care expenditures, or $\$ 52$ billion in 1995 dollars. ${ }^{68}$ More conservative estimates still suggest that obesity accounts for $1 \%$ to $4 \%$ of total health care costs. ${ }^{7}$ Notwithstanding these enormous costs, Congress and state legislatures provide virtually no funding specifically targeted to anti-obesity measures other than basic research. The $\$ 5$ million recently granted to the CDC for nutrition and obesity programs represents a small but important step in the right direction.

To compensate for state and federal legislatures' failure to apply general revenues to anti-obesity measures, other commentators have suggested that revenues from taxes on "junk foods" be used to subsidize the costs of more healthful foods. ${ }^{31}$ While onerous taxes on commonly purchased products would be highly unpopular and politically unreal- 


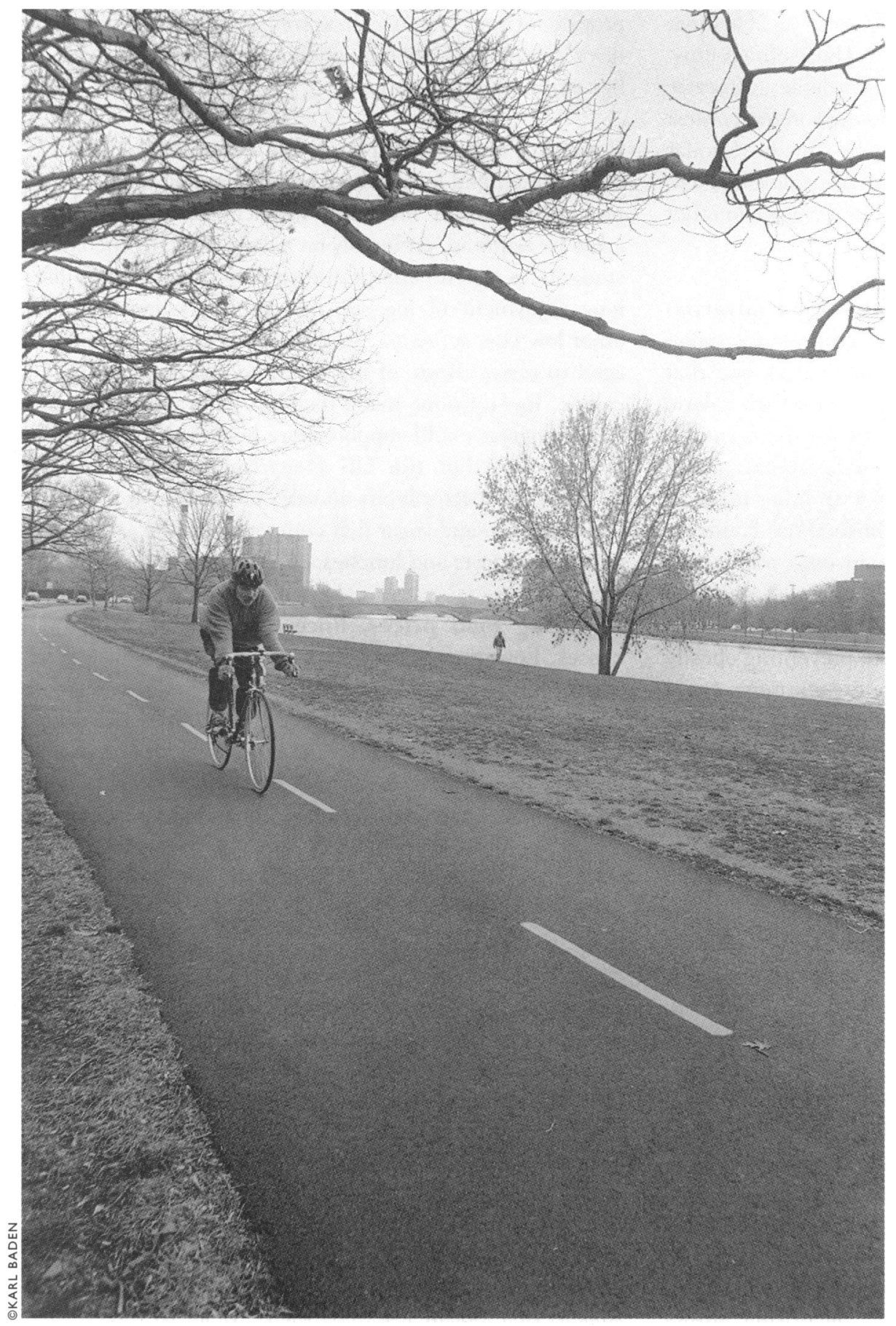

this tax alone raises about $\$ 200$ million per year. A two-cent-percan tax on soft drinks in Arkansas raises $\$ 40$ million per year (Personal communication, Tamra Huff, Arkansas Department of Finance and Administration, September 1998). In these and several other states, the tax revenues go into the general treasury. West Virginia, however, uses the revenues from its soft drink tax to support its state medical, dental, and nursing schools, and Tennessee earmarks $21 \%$ of the revenues from its tax for cleaning up highway litter.

To fund the television advertisements, physical education teachers, bicycle paths, swimming pools, and other measures that we propose, we suggest that small taxes be levied on several widely used products that are likely to contribute to obesity. We estimate that each of the following hypothetical taxes would generate revenues of about $\$ 1$ billion per year:

- A 2/3-cent tax per $12 \mathrm{oz}$ on soft drinks. $^{70}$

- A 5\% tax on new televisions and video equipment. ${ }^{43}$

- A $\$ 65$ tax on each new motor vehicle (about $0.3 \%$ on a $\$ 20,000$ car), or an extra penny tax per gallon of gasoline. ${ }^{43}$

A national survey found that $45 \%$ of adults would support a one-cent tax on a can of soft

istic, small taxes are feasible. Such taxes would likely have little effect on overall sales but could generate sufficient revenues to fund some of the measures that we are suggesting. Legislatures have long levied taxes on products deemed to be unhealthful. Thus, the federal government and states impose taxes on alcoholic beverages and cigarettes; these taxes are supported by large public majorities, especially when the revenues are earmarked for health purposes. ${ }^{69}$ Several states currently tax soft drinks and snack foods. In California, for example, soft drinks are the only foods subject to the $7.25 \%$ sales tax; we calculate on the basis of population ${ }^{43}$ and consumption ${ }^{70}$ statistics that drink, pound of potato chips, or pound of butter if the revenues funded a national health education program. ${ }^{71}$ Such taxes are too small to raise serious concerns about their regressive nature.

\section{Toward national action}

The USDA and DHHS have announced plans for a National Nutrition Summit, scheduled for May 30-31, 2000. This Summit could catalyze an unprecedented effort to reverse the obesity epidemic. Its focus will be on behavioral factors-especially those that could help pre- 
vent overweight and obesity. ${ }^{72}$ The Summit provides an ideal opportunity for public and private institutions to initiate the kinds of policies and programs that we are advocating. We believe that the Summit should emphasize ways to improve both government policies and corporate practices that affect individual behavior change.

Government officials could use the Summit to announce actions, including proposed legislation, that their departments will seek to implement (see Figure 3). For example, USDA could announce incentives to encourage Food Stamp recipients to buy more produce, whole grains, and reduced-fat animal products. The Surgeon General could announce a campaign to reduce television watching. Justice Department officials could announce initiatives for reducing inner-city crime to make playing outside safer for children, while the Department of Housing and Urban Development could announce grants for inner-city recreational facilities. The Department of Transportation could announce increased funding to enable states to expand mass transit and provide more bicycle paths. Finally, the futility of current efforts demonstrates the urgent need for research on which to base more effective public health policies. Ending the obesity epidemic will require much greater knowledge of effective diet and activity strategies than is currently available. The research focus must extend beyond genetic, metabolic, and drug development studies to encompass-and emphasize- population-based behavioral interventions, policy development, and program evaluation.

Thus, we propose that the measures outlined in Figure 3 be implemented on a trial basis and evaluated for their effectiveness. We do not pretend that these suggestions alone will eliminate obesity from American society, but they will be valuable if they help to produce even small reductions in the rate of obesity, as even modest weight loss confers substantial health and economic benefits. ${ }^{73}$ Without such a national commitment and effective new approaches to making the environment more favorable to maintaining healthy weight, we doubt that the current trends can be reversed.

This analysis was supported in part by research challenge grants from New York University (NYU) and the NYU School of Education. The authors thank Margo Wootan, DSc, of the Center for Science in the Public Interest (CSPI), for her contributions to the policy suggestions, and Suzanne Rostler of NYU, Stacey Freis of NYU, and Geoffrey Barron of CSPI for research assistance.

Dr. Nestle is Professor and Chair, Department of Nutrition and Food Studies, New York University. Dr. Jacobson is the Executive Director, Center for Science in the Public Interest, Washington, DC.

Address correspondence to: Dr. Nestle, Dept. of Nutrition and Food Studies, NYU, New York NY 100 12; tel. 212-998-5595; fax 212-9954194; e-mail <marion.nestle@nyu.edu>.
I. Infant and adult obesity [editorial]. Lancet 1974;i:17-18.

2. Mokdad AH, Serdula MK, Dietz WH, Bowman BA, Marks JS, Koplan JP. The spread of the obesity epidemic in the United States, 1991-1998. JAMA 1999;282:1519-22.

3. Troiano RP, Flegal KM, Kuczmarski RJ, Campbell SM, Johnson CL. Overweight prevalence and trends for children and adolescents. Arch Pediatr Adolesc Med 1995; 149:1085-91.

4. Update: prevalence of overweight among children, adolescents, and adults-United States, 1988-1994. MMWR Morb Mortal Wkly Rep 1997;46:199-202.

5. Must A, Spadano J, Coakley EH, Field AE, Colditz G, Dietz WH. The disease burden associated with overweight and obesity. JAMA 1999;282:1523-9.

6. Allison DB, Fontaine KR, Manson JE, Stevens J, Vanltallie TB. Annual deaths attributable to obesity in the United States. JAMA 1999;282: 1530-8.

7. Allison DB, Zannolli R, Narayan KMV. The direct health care costs of obesity in the United States. Am J Public Health 1999;89:1 194-9.

8. Rippe JM, Aronne LJ, Gilligan VF, Kumanyika S, Miller S, Owens GM, et al. Public policy statement on obesity and health from the Interdisciplinary Council on Lifestyle and Obesity Management. Nutr Clin Care 1998;1:34-7.

9. Grundy SM. Multifactorial causation of obesity: implications for prevention. Am J Clin Nutr 1998;67(3 Suppl):536S-72S.

10. Whitaker RC, Wright JA, Pepe MS, Seidel KD, Dietz WH. Predicting obesity in young adulthood from childhood and parental obesity. N Engl J Med 1997;337:869-73.

11. Methods for voluntary weight loss and control: Technology Assessment Conference statement. Bethesda (MD): National Institutes of Health (US); 1992.
12. Williamson DF. Pharmacotherapy for obesity. JAMA 1999;281:278-80.

13. Expert Panel on the Identification, Evaluation, and Treatment of Overweight in Adults. Clinical guidelines on the identification, evaluation, and treatment of overweight in adults. Bethesda (MD): National Institutes of Health (US); 1998.

14. US Preventive Services Task Force. Guide to clinical preventive services. 2nd ed. Alexandria (VA): International Medical Publishing; 1996.

15. Dalton S. Overweight and weight management. Gaithersburg (MD): Aspen; 1997.

16. Koplan JP, Dietz WH. Caloric imbalance and public health policy. JAMA 1999;282:1579-80.

17. Harvard School of Public Health, Department of Nutrition. Food for your heart: a manual for patient and physician. New York: American Heart Association; 1952.

18. Senate Select Committee on Nutrition and Human Needs (US). Dietary goals for the United States. 2nd ed. Washington: Government Printing Office; 1977.

19. White House Conference on Food, Nutrition, and Health: final report. Washington: Government Printing Office; 1970.

20. Stunkard AJ. Obesity and the social environment: current status, future prospects. In: Bray GA, editor. Obesity in America. Washington: Department of Health, Education, and Welfare (US); 1979. NIH Pub. No.: 79-359.

21. Stunkard A. The social environment and the control of obesity. In: Stunkard AJ, editor. Obesity. Philadelphia: WB Saunders; 1980. p. 43862.

22. Fullarton JE. Matrix for action: nutrition and dietary practices [appendix]. In: Bray GA, editor. Obesity in America. Washington: Department of Health, Education, and Welfare (US); 1979. p. 241-64. NIH Pub. No.: 79-359. 
23. Department of Health and Human Services (US). Promoting health/preventing disease: objectives for the nation. Washington: Government Printing Office; 1980.

24. Department of Agriculture (US) and Department and Health and Human Services (US). Nutrition and your health: dietary guidelines for Americans. Washington: Government Printing Office; 1980.

25. Department of Health and Human Services (US). Promoting health/preventing disease: Public Health Service implementation plans for attaining the objectives for the nation. Public Health Rep 1983;Sept-Oct Suppl.

26. Department of Health and Human Services (US). Healthy People: national health promotion and disease prevention objectives. Washington: Government Printing Office; 1990.

27. Department of Health and Human Services (US). The 1990 Health Objectives for the Nation: a midcourse review. Washington: Office of Disease Prevention and Health Promotion (US); 1986.

28. Life Sciences Research Office, Federation of American Societies for Experimental Biology. Third report on nutrition monitoring in the United States. Vol 2. Prepared for Interagency Board for Nutrition Monitoring and Related Research, US Department of Health and Human Services, US Department of Agriculture. Washington: Government Printing Office; 1995.

29. Department of Agriculture (US). Data Tables: Results from USDA's 1994-96 Continuing Survey of Food Intakes by Individuals and 1994-96 Diet and Health Knowledge Survey, December 1997 [cited 1999 Feb 23]. Available from: URL: http://www.barc.usda.gov/bhnrc/food survey/home.htm

30. Department of Health and Human Services (US). Healthy People 2010: understanding and improving health. Conference edition. Washington: Government Printing Office; 2000.

31. Battle EK, Brownell KD. Confronting a rising tide of eating disorders and obesity: treatment vs. prevention and policy. Addict Behav 1996;21:755-65.

32. Department of Agriculture, Economic Research Service (US). U.S. Food Expenditures [cited 1999 Dec II]. Available from: URL: http://www. econ.ag.gov

33. Gallo AE. The food marketing system in 1996. Agricultural Information Bulletin No. 743. Washington: Department of Agriculture (US); 1998.

34. 44th annual: 100 leading national advertisers. Advertising Age 1999 Sept 27;SI-S46.

35. Gov't \& industry launch fruit and vegetable push; but $\mathrm{NCl}$ takes back seat. Nutr Week 1992;22(26): I-2.

36. Cleeman JI, Lenfant C. The National Cholesterol Education Program: progress and prospects. JAMA 1998;280:2099-104.

37. Kotz K, Story M. Food advertisements during children's Saturday morning television programming: are they consistent with dietary recommendations? J Am Diet Assoc 1994;94:1296-1300.

38. Hays CL. Channel One's mixed grades in schools. New York Times 1999 Dec 5;Sect. C:I,14-15.

39. Hays CL. Be true to your cola, rah! rah!: battle for soft-drink loyalties moves to public schools. New York Times 1998 Mar 8;Sect. D:I,4.

40. Sylvester GP, Achterberg C, Williams J. Children's television and nutrition: friends or foes. Nutr Today 1995;30(1):6-15.

41. McNeal JU. The kids market: myths and realities. Ithaca (NY): Paramount Market Publishing; 1999.

42. Lin B-H, Frazão E, Guthrie J. Away-from-home foods increasingly important to quality of American diet. Agricultural Information Bulletin No. 749. Washington: Department of Agriculture (US); 1999.

43. Bureau of the Census (US). Statistical abstract of the United States: the national data book: 1997. I17th ed. Washington: Government Printing Office; 1997.

44. Vended bottled drinks. Vending Times 1998;38(9):15,21-2.

45. Annual Report. Atlanta: Coca-Cola Co.; 1997. Available from CocaCola Co., One Coca-Cola Plaza, Atlanta GA 30313.

46. Burros $M$. Losing count of calories as plates fill up. New York Times 1997 Apr 2;Sect. C:I,4.

47. National Research Council. Recommended dietary allowances. 9th rev. ed. Washington: National Academy Press; 1989.
48. Young LR, Nestle M. Portion sizes in dietary assessment: issues and policy implications. Nutr Rev 1995;53:149-58.

49. Jacobson MF. Liquid candy: how soft drinks are harming Americans' health. Washington: Center for Science in the Public Interest; 1998.

50. President's Council on Physical Fitness and Sports (US). Physical activity and health: a report of the Surgeon General. Washington: Department of Health and Human Services (US); 1996.

51. Neighborhood safety and the prevalence of physical inactivity-selected states, 1996. MMWR Morb Mortal Wkly Rep 1999;48:143-6.

52. Welcome to Shape Up America! [cited 1999 Dec 4]. Available from: URL: http://www.shapeup.org

53. Jeffery RW. Public health approaches to the management of obesity. In: Brownell KD, Fairburn CG, editors. Eating disorders and obesity: a comprehensive handbook. New York: Guilford Press; 1995. p. 558-63.

54. Hirsch J. Obesity prevention initiative. Obes Res 1994;2:569-84.

55. Zepezauer M, Naiman A. Take the rich off welfare. Tucson (AZ): Odonian Press; 1996.

56. Reger B, Wootan MG, Booth-Butterfield S. Using mass media to promote healthy eating: a community-based demonstration project. Prev Med 1999;29:414-2I.

57. Reger B, Wootan MG, Booth-Butterfield S, Smith H. I\% or less: a community-based nutrition campaign. Public Health Rep 1998;1 13:410-19.

58. Nestle M. Toward more healthful dietary patterns-a matter of policy. Public Health Rep 1998; I 3;420-3.

59. McClain DL. Where is today's child? probably watching TV. New York Times 1999 Dec 6;Sect. C:18.

60. Anderson RE, Crespo CJ, Bartlett SJ, Cheskin LJ, Pratt M. Relationship of physical activity and television watching with body weight and level of fatness among children: results from the Third National Health and Nutrition Examination Survey. JAMA 1998;279:938-42.

61. Jeffery RW, French SA. Epidemic obesity in the United States: are fast foods and television viewing contributing? Am J Public Health 1998;88:277-80.

62. Robinson TN. Reducing children's television viewing to prevent obesity: a randomized controlled trial. JAMA 1999;282:1561-7.

63. Ryan M. Are you ready for TV-Turnoff Week? Parade 1998 Apr 12;1819.

64. Fox RF. Harvesting minds: how TV commercials control kids. Westport (CN): Praeger; 1996.

65. Federal Trade Commission Improvements Act of 1980, Pub. L. No. 96252, 94 Stat. 374 (1980).

66. French SA, Story M, Jeffery RW, Snyder P, Eisenberg M, Sidebottom A, Murray $D$. Pricing strategy to promote fruit and vegetable purchase in high school cafeterias. J Am Diet Assoc 1997;97:1008-10.

67. French SA, Jeffery RW, Story M, Hannan P, Snyder M. A pricing strategy to promote low-fat snack choices through vending machines. Am J Public Health 1997;87:849-51.

68. Wolf AM, Colditz GA. Current estimates of the economic cost of obesity in the United States. Obes Res 1998;6:97-106.

69. Conference Research Center. Special consumer survey report: to tax or not to tax. New York: Conference Board; 1993 Jun.

70. Putnam JJ, Allshouse JE. Food consumption, prices, and expenditures, 1970-97. Statistical Bulletin No. 965. Washington: Department of Agriculture (US); 1999.

71. Bruskin-Goldring Research. Potato chip labels/health programs, January 30-31, 1999. Edison (NJ): Center for Science in the Public Interest; 1999.

72. Department of Agriculture (US) and Department of Health and Human Services (US). National Nutrition Summit: notice of a public meeting to solicit input in the planning of a National Nutrition Summit. Fed Reg 1999;64(Nov 26):6645।.

73. Oster G, Thompson D, Edelsberg J, Bird AP, Colditz GA. Lifetime health and economic benefits of weight loss among obese persons. Am J Public Health 1999;89:1536-42. 